\title{
The Effect of Kinesio Taping on Quadriceps Femoris Muscle Power and Strength in Non-Athlete Adult Males
}

\author{
Julia W Gunadi*, Yenni Limyati**, Jeanny E Ladi***, \\ Stela Clara****, Hadrian M Sinaga**** \\ * Physiology Department Faculty of Medicine Maranatha Christian University \\ ** Physical Medicine and Rehabilitation Department Immanuel Hospital Bandung \\ ** Histology Department Faculty of Medicine Maranatha Christian University \\ **** Faculty of Medicine Maranatha Christian University \\ Jalan Prof. drg. Suria Sumantri MPH No. 65 Bandung 40164 Indonesia \\ Email: juliawindig@gmail.com
}

\begin{abstract}
The use of Kinesio Taping has been reported to increase muscle power and strength, especially quadriceps femoris muscle, the great extensor of the leg. This research examines the effect of Kinesio Taping on quadriceps femoris muscle power and strength in non-athlete adult males. This research is quasi experimental design, involving 30 non-athlete adult males aged 18-22 years old. Muscle power is examined by using Margaria-KalamenPower Test, and muscle strength by using Isometric Leg Strength Test before, 20 minutes and 24 hours after using Kinesio Taping. The data is analyzed by using paired t test. The result shows that muscle power difference between 20 minutes and before using KinesioTaping $(196,62 \pm 150,67)$ watt are lower than muscle power difference between 24 hours and before using KinesioTaping $(247,31 \pm 139,88)$ watt ( $p$ value $<0,01$ ). The result also shows that muscle strength difference between 20 minutes and before using KinesioTaping $(26,74 \pm 10,26) \mathrm{kg}$ shows lower than muscle strength difference between 24 hours and before using KinesioTaping $(30,26 \pm 9,99) \mathrm{kg}(p$ value $<0,01)$. KinesioTaping increases quadriceps femoris muscle power and strength 24 hours after better than 20 minutes after using in non-athlete adult males.
\end{abstract}

Keywords: Kinesio Taping, quadriceps femoris, muscle power, muscle strength 


\title{
Pengaruh Penggunaan Kinesio Taping terhadap Daya Ledak dan Kekuatan Otot Quadriceps Femoris pada Laki-Laki Dewasa Non Atlet
}

\author{
Julia W Gunadi*, Yenni Limyati**, Jeanny E Ladi***, \\ Stela Clara****, Hadrian M Sinaga**** \\ * Bagian Ilmu Faal Fakultas Kedokteran Universitas Kristen Maranatha \\ ** Bagian Rehabilitasi Medik Rumah Sakit Immanuel Bandung \\ ** Bagian Histologi Fakultas Kedokteran Universitas Kristen Maranatha \\ **** Fakultas Kedokteran Universitas Kristen Maranatha \\ Jalan Prof. drg. Suria Sumantri MPH No. 65 Bandung 40164 Indonesia \\ Email: juliawindig@gmail.com
}

\begin{abstract}
Abstrak
Penggunaan Kinesio Taping dilaporkan dapat meningkatkan daya ledak dan kekuatan otot, terutama otot quadriceps femoris, yang merupakan otot besar tungkai. Tujuan penelitian ini adalah untuk mengetahui pengaruh penggunaan Kinesio Taping terhadap daya ledak dan kekuatan otot quadriceps femoris pada laki-laki dewasa non atlet. Penelitian ini bersifat eksperimental semu, dengan subjek penelitian 30 orang laki-laki non atlet berusia 18-22 tahun. Pengukuran daya ledak otot dilakukan dengan Margaria-Kalamen Power Test, dan kekuatan otot dengan Isometric Leg Strength Test saat sebelum, 20 menit dan 24 jam sesudah penempelan Kinesio Taping. Data dianalisis dengan uji t berpasangan. Hasil penelitian menunjukkan selisih daya ledak otot 20 menit dengan sebelum penggunaan Kinesio Taping $(196,62 \pm 150,67)$ watt lebih rendah daripada selisih daya ledak otot 24 jam dengan sebelum penggunaan Kinesio Taping $(247,31 \pm 139,88)$ watt $(\mathrm{p}<0,01)$. Selisih kekuatan otot 20 menit dengan sebelum penggunaan Kinesio Taping $(26,74 \pm 10,26) \mathrm{kg}$ lebih rendah daripada selisih kekuatan otot 24 jam dengan sebelum penggunaan Kinesio Taping $(30,26 \pm 9,99) \mathrm{Kg}(\mathrm{p}<0,01)$. Penggunaan 24 jam Kinesio Taping meningkatkan daya ledak dan kekuatan otot quadriceps femoris lebih baik daripada penggunaan 20 menit pada laki-laki dewasa non atlet.
\end{abstract}

Kata kunci: Kinesio Taping, otot quadriceps femoris, daya ledak otot, kekuatan otot 


\section{Research Article}

\section{Pendahuluan}

Daya ledak dan kekuatan otot merupakan dua hal yang saling berhubungan dan tentu saja dapat meningkatkan performa otot secara keseluruhan, terutama performa otot quadriceps femoris yang sangat dibutuhkan dalam aktivitas sehari-sehari. Otot quadriceps femoris disebut sebagai the great extensor of the leg, karena berfungsi menggerakkan panggul dan lutut. Otot rectus femoris berfungsi untuk fleksi panggul dan ekstensi lutut, sedangkan otot vastus intermedius, vastus medialis, dan vastus lateralis membentuk otot ekstensor utama pada lutut. Sendi lutut relatif lemah secara mekanik karena inkongruensi dari permukaan sendinya, karena itu kestabilannya tergantung kekuatan dari otot sekelilingnya, terutama otot quadriceps femoris. Kontraksi konsentrik otot quadriceps femoris saat ekstensi lutut melawan gravitasi, penting saat bangun dari posisi duduk atau jongkok, berjalan naik tangga, mendaki, dan untuk akselerasi dan proyeksi (lari dan lompat) saat mengangkat atau memindahkan berat tubuh. Otot ini dikatakan tiga kali lipat lebih kuat dibandingkan dengan otot antagonisnya, yaitu otot hamstrings. ${ }^{1}$

Kinesio ${ }^{\circledR}$ tex tape merupakan tape elastik tipis yang memiliki kemampuan regangan hingga $140 \%$ dari ukuran sebenarnya, sehingga tidak membatasi pergerakan sendi. ${ }^{2}$ Pengaruh Kinesio Taping terhadap performa otot masih kontroversial, beberapa peneliti berpendapat bahwa Kinesio Taping dapat memfasilitasi peningkatan daya ledak dan kekuatan otot dengan menghasilkan penarikan konsentrik fascia yang kemudian meningkatkan kontraksi otot. ${ }^{3}$ Slupik et al mendemonstrasikan peningkatan torsi puncak (24 jam) dan aktivitas elektromiograf (72 jam) pada otot vastus medialis setelah pemasangan Kinesio Taping. ${ }^{4}$ Huang et al meneliti pengaruh Kinesio Taping terhadap otot triseps surae saat melompat vertikal maksimal, dan didapatkan aktivitas elektromiografi otot gastrocnemius medialis meningkat saat dipasang Kinesio Taping, namun tinggi lompatan tetap konstan. ${ }^{5}$

Penelitian yang dilakukan oleh Fu et al mengenai efek Kinesio Taping terhadap kekuatan otot quadriceps dan hamstrings pada atlet, yang diukur segera dan 12 jam setelah pemasangan dibandingkan tanpa Kinesio Taping, didapatkan hasil tidak ada perbedaan yang signifikan. ${ }^{6}$ Chang et al mengevaluasi efek Kinesio Taping terhadap grip kekuatan maksimal tangan dominan pada mahasiswa atlet yang sehat, dan didapatkan tidak ada perbedaan yang bermakna. ${ }^{7}$ Beberapa penelitian yang menunjukkan tidak ada peningkatan daya ledak dan kekuatan otot setelah pemasangan Kinesio Taping, dilakukan pada atlet, yang diasumsikan telah memiliki daya ledak dan kekuatan otot yang baik. Hal ini menyebabkan efek peningkatan daya ledak dan kekuatan otot pada atlet tersebut menjadi tidak bermakna. Oleh karena itu, penelitian ini dilakukan pada subjek non atlet, dengan asumsi bahwa peningkatan daya ledak dan kekuatan otot akan lebih mudah terdeteksi dibandingkan pada atlet profesional. 
Kase dan Hashimoto menyatakan bahwa Kinesio Taping memiliki efek meningkatkan aliran darah 10 menit setelah pemasangan, dan efek tersebut meningkat seiring dengan lamanya waktu pemasangan Kinesio Taping. Waktu rata-rata yang diperlukan untuk terjadinya efek fasilitasi dari Kinesio Taping adalah 20 menit setelah pemasangan, dan efek ini bertahan hingga 24 jam setelah pemasangan. ${ }^{8}$ Berbeda dengan penelitian sebelumnya, yang meneliti efek langsung dari Kinesio Taping, maka penelitian ini ingin mengetahui efek Kinesio Taping 20 menit setelah pemasangan, dan apakah efek tersebut bertahan hingga 24 jam setelah pemasangan.

\section{Metode}

Desain penelitian yang diterapkan pada penelitian ini adalah quasi experimental design. Penelitian ini dilakukan di Fakultas Kedokteran Universitas Kristen Maranatha dan berlangsung dari bulan Januari 2016 hingga November 2016. Sampel penelitian adalah 30 orang laki-laki non atlet berusia 18-22 tahun di Universitas Kristen Maranatha.

Alat dan bahan yang digunakan pada percobaan ini adalah tali/pita pengukur, stopwatch, tangga dengan jumlah anak tangga minimal 9 dan tinggi setiap anak tangga 17,8 cm, lintasan lurus dan datar dengan starting line yang berjarak 6 meter dari anak tangga pertama, leg and back dynamometer, Kinesio ${ }^{\circledR}$ Tex Tape, timbangan, kapas, dan alkohol $70 \%$.

Subjek penelitian adalah 30 orang laki-laki non atlet berusia 18-22 tahun di Universitas Kristen Maranatha yang memenuhi kriteria inklusi: sehat jasmani, memiliki IMT normal (18,5$22,9)$, bersedia menjadi subjek penelitian secara sukarela dan menandatangani surat persetujuan penelitian yang telah disahkan oleh Komisi Etik Fakultas Kedokteran Universitas Kristen Maranatha dan kriteria eksklusi: mengalami paraplegi/paraparesis, mengalami kelelahan otot quadriceps femoris, memiliki riwayat trauma ekstremitas superior dan/atau vertebrae lumbalis, pernah dilakukan operasi pada ekstremitas superior, atlet atau orang yang fisiknya terlatih, dan alergi terhadap Kinesio ${ }^{\circledR}$ Tex Tape.

Pada penelitian ini, pengukuran daya ledak dan kekuatan otot dilakukan secara pre-test dan post-test dengan total pengukuran sebanyak 3 kali, yaitu satu kali sebelum penempelan Kinesio Taping, satu kali setelah 20 menit penempelan Kinesio Taping, dan satu kali setelah 24 jam penempelan Kinesio Taping dengan menggunakan metode Margaria-Kalamen Power Test untuk pengukuran daya ledak otot, dan metode Isometric Leg Strength Test untuk pengukuran kekuatan otot.

Pada metode Margaria-Kalamen Power Test, subjek penelitian diposisikan pada starting line yang berjarak $6 \mathrm{~m}$ dari anak tangga yang pertama, lalu subjek penelitian diminta 


\section{Research Article}

untuk berlari dan menaiki tangga secepat mungkin dengan ketentuan tiga anak tangga dalam satu kali melangkah dan dilakukan hingga anak tangga ke sembilan. Penghitungan waktu dimulai ketika subjek penelitian menginjak anak tangga yang ketiga dan dihentikan ketika subjek penelitian menginjak anak tangga kesembilan. Tes dilakukan sebanyak tiga kali dengan selang waktu antara masing-masing tes adalah 2-3 menit. Waktu yang didapat dalam detik (t) selanjutnya dikonversi menjadi daya ledak otot dengan memasukkannya ke dalam rumus sebagai berikut:

$$
\begin{gathered}
P=\frac{(m \times 9.8) h}{t} \\
\mathrm{P}=\text { daya ledak (watt) } \\
\mathrm{m}=\text { massa Tubuh }(\mathrm{kg}) \\
\mathrm{h}=\text { jarak vertikal }(\mathrm{m}) \\
\mathrm{t}=\text { waktu (detik) }
\end{gathered}
$$

Ketiga hasil daya ledak otot yang diperoleh selanjutnya dihitung reratanya. ${ }^{9}$
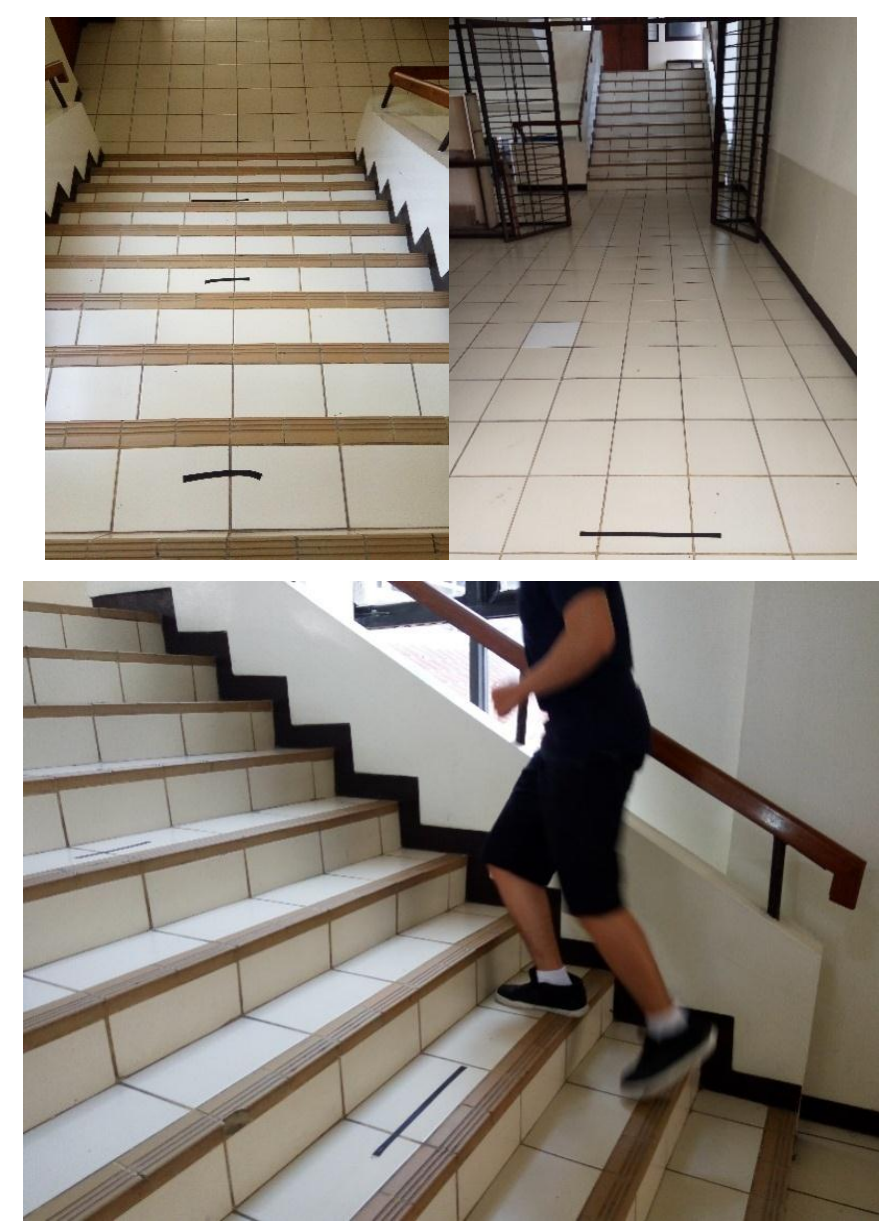

Gambar 1 Prosedur Margaria-Kalamen Power Test 


\section{Research Article}

Untuk mengukur kekuatan otot, digunakan Isometric Leg Strength Test dengan cara subjek penelitian berdiri di atas dasar leg \& back dynamometer dengan posisi punggung lurus dan kedua kaki dibuka selebar bahu dan batang pegangan leg \& back dynamometer digenggam. Batang pegangan leg \& back dynamometer kemudian ditempatkan di atas paha subjek penelitian dan panjang rantai yang akan dikaitkan pada alat leg \& back dynamometer diatur sehingga lutut subjek penelitian berada pada posisi fleksi sebesar $110^{\circ}$. Kemudian subjek penelitian diposisikan ekstensi lutut dengan lengan dan punggung tetap lurus dan gerakan ini ditahan selama 5 detik untuk mendapatkan hasil maksimal. Pengambilan data dilakukan sebanyak tiga kali dengan jeda istirahat selama satu menit sebelum melakukan pengukuran kembali, kemudian data yang diperoleh dihitung rata-ratanya. ${ }^{10}$

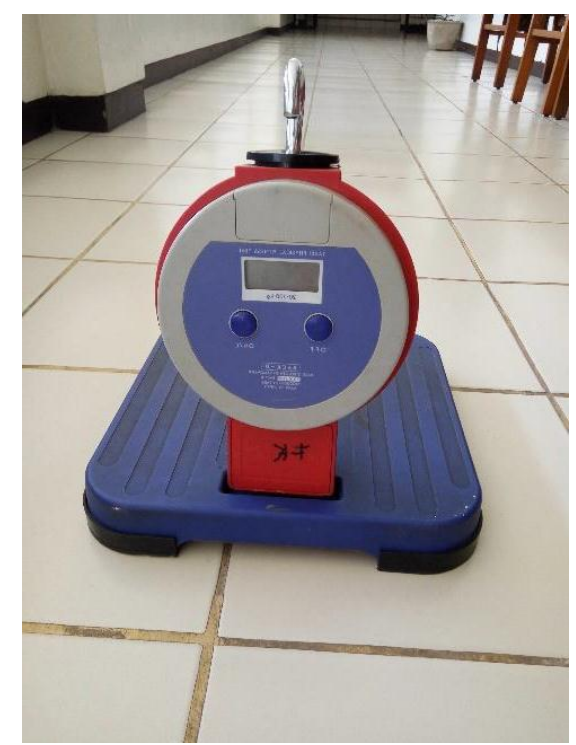

Gambar 2 Leg and Back Dynamometer

Kinesio $^{\circledR}$ Tex Tape pada percobaan ini akan dipasang pada m.quadriceps femoris, dengan menggunakan teknik "I" dengan arah dari origo menuju ke insersi dan Kinesio ${ }^{\circledR}$ Tex Tape diregangkan sebesar 25\%. Sebelum dilakukan pemasangan Kinesio ${ }^{\circledR}$ Tex Tape, lokasi tempat pemasangan Kinesio ${ }^{\circledR}$ Tex Tape harus dibersihkan terlebih dahulu dari keringat dan minyak dengan menggunakan alkohol $70 \%$ agar agar Kinesio ${ }^{\circledR}$ Tex Tape dapat menempel dengan baik pada kulit. ${ }^{8}$

Data yang diperoleh dianalisis dengan One-Way ANOVA dan posthoc test Fisher's LSD menggunakan program SPSS (IBM ${ }^{\circledR}$ SPSS $^{\circledR}$ version 23) dengan $\alpha=0,05$. Kemaknaan ditentukan 


\section{Research Article}

berdasarkan $\mathrm{p}<0,05$. Penelitian ini telah mendapat persetujuan dari Komisi Etik Universitas Kristen Maranatha dengan surat keputusan komisi etik nomor: 060/KEP/IV/2016 dan nomor 187/KEP/VIII/2016.

\section{Hasil}

Seluruh data mengenai besarnya daya ledak otot yang terdiri dari daya ledak otot sebelum penggunaan, 20 menit setelah penggunaan, dan 24 jam setelah penggunaan Kinesio Taping telah melalui uji normalitas dan diperoleh nilai $\mathrm{p}>0,05$ baik untuk daya ledak otot sebelum penggunaan, 20 menit setelah penggunaan, maupun 24 jam setelah penggunaan Kinesio Taping, yaitu masing-masing sebesar 0,$083 ; 0,135 ; 0,200$. Dengan demikian, dapat disimpulkan bahwa seluruh data terdistribusi normal dan dapat dilakukan uji statistik parametrik menggunakan $\mathrm{t}$ test berpasangan.

Hasil penelitian yang telah dilakukan pada 30 orang laki-laki non atlet berusia 18-22 tahun diperoleh perbandingan selisih daya ledak otot 20 menit setelah dengan sebelum penggunaan Kinesio Taping, dan selisih 24 jam setelah dengan sebelum penggunaan Kinesio Taping ditampilkan pada gambar 2.

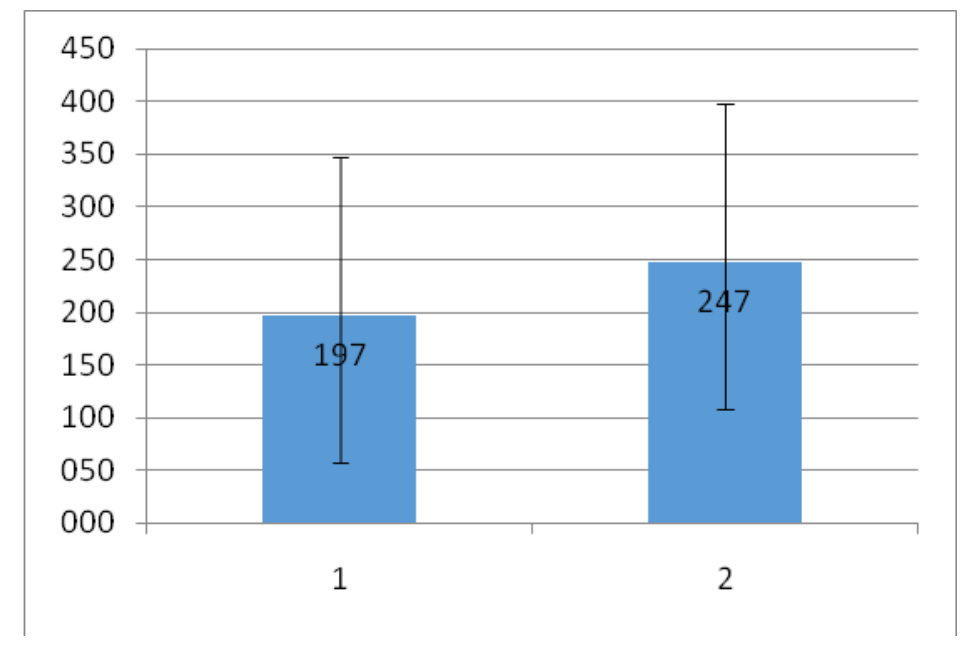

\section{Gambar 2 Selisih Daya Ledak 20 Menit Setelah dengan Sebelum dan 24 Jam Setelah dengan Sebelum Penggunaan Kinesio Taping}


Tabel 1 Tabel Hasil Uji Statistik Daya Ledak Otot dengan t-Test Berpasangan

\begin{tabular}{|c|c|c|c|c|}
\hline Daya Ledak Otot & Mean (Watt) & Standar Deviasi & $\mathrm{p}$ value & $\mathrm{N}$ \\
\hline $\begin{array}{c}\text { Selisih } 20 \text { menit setelah dengan } \\
\text { sebelum pemasangan Kinesio Taping }\end{array}$ & 196,62 & 150,67 & & \\
\hline $\begin{array}{c}\text { Selisih } 24 \text { jam setelah dengan } \\
\text { sebelum pemasangan Kinesio Taping }\end{array}$ & 247,31 & 139,88 & $0,009 * *$ & 30 \\
\hline $\begin{array}{ll}\text { Keterangan: } \\
* & \text { : Perbedaan bermakna dengan nilai } \mathrm{p} \\
* * & \text { : Perbedaan sangat bermakna dengan } \\
\mathrm{ns} & \text { : Perbedaan tidak bermakna dengan } \mathrm{n}\end{array}$ & $\begin{array}{l}05 \\
\text { ai } p<0,01 \\
p>0,05\end{array}$ & & & \\
\hline
\end{tabular}

Hasil uji statistik terhadap selisih daya ledak otot 20 menit setelah dengan sebelum penggunaan Kinesio Taping, dan selisih 24 jam setelah dengan sebelum penggunaan Kinesio Taping dengan $t$ test berpasangan menghasilkan nilai $\mathrm{p}<0,01$. Hal ini menunjukkan terdapat perbedaan yang sangat bermakna antara selisih daya ledak otot 20 menit setelah dengan sebelum penggunaan Kinesio Taping, dan selisih 24 jam setelah dengan sebelum penggunaan Kinesio Taping.

Sebelum melakukan uji statistik t test berpasangan, data mengenai besarnya kekuatan otot sebelum penggunaan, 20 menit setelah penggunaan, dan 24 jam setelah penggunaan Kinesio Taping telah melalui uji normalitas dan diperoleh nilai $\mathrm{p}>0,05$ baik untuk kekuatan otot sebelum penggunaan, 20 menit setelah penggunaan, maupun 24 jam setelah penggunaan Kinesio Taping, yaitu masing-masing sebesar 0,$063 ; 0,336 ; 0,085$. Berdasarkan hasil uji normalitas yang telah dilakukan, dapat disimpulkan bahwa seluruh data terdistribusi normal.

Hasil pengukuran kekuatan otot pada 30 orang laki-laki non atlet berusia 18-22 tahun diperoleh hasil perbandingan selisih kekuatan otot 20 menit setelah dengan sebelum penggunaan Kinesio Taping, dan selisih 24 jam setelah dengan sebelum penggunaan Kinesio Taping sebagai berikut:

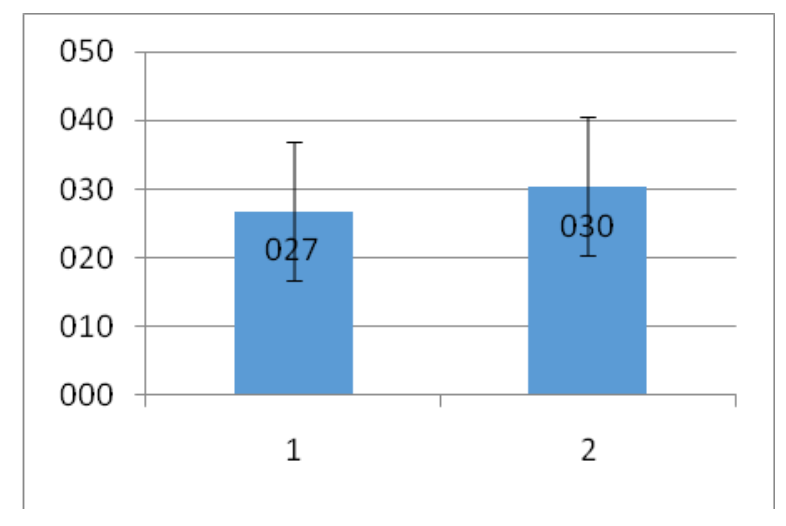

Gambar 3 Selisih Kekuatan Otot 20 Menit Setelah dengan Sebelum dan 24 Jam Setelah
dengan Sebelum Penggunaan Kinesio Taping 
Tabel 2 Tabel Hasil Uji Statistik Kekuatan Otot dengan t-Test Berpasangan

\begin{tabular}{|c|c|c|c|c|}
\hline Kekuatan Otot & Mean $(\mathrm{Kg})$ & Standar Deviasi & $\mathrm{P}$ value & $\mathrm{N}$ \\
\hline $\begin{array}{c}\text { Selisih } 20 \text { menit setelah dengan } \\
\text { sebelum pemasangan Kinesio Taping }\end{array}$ & 26,74 & 10,26 & & \\
\hline $\begin{array}{c}\text { Selisih } 24 \text { jam setelah dengan sebelum } \\
\text { pemasangan Kinesio Taping }\end{array}$ & 30,26 & 9,99 & $0,003 * *$ & 30 \\
\hline $\begin{array}{ll}\text { Keterangan: } \\
* & : \text { Perbedaan bermakna dengan nilai } \mathrm{p}< \\
* * & : \text { Perbedaan sangat bermakna dengan } n \\
\mathrm{~ns} & : \text { Perbedaan tidak bermakna dengan ni }\end{array}$ & 00,01 & & & \\
\hline
\end{tabular}

Hasil uji statistik yang menggunakan uji t test berpasangan menghasilkan nilai $\mathrm{p}<0,01$. Hal menunjukkan terdapat perbedaan yang sangat bermakna antara selisih kekuatan otot 20 menit setelah dengan sebelum penggunaan Kinesio Taping, dan selisih 24 jam setelah dengan sebelum penggunaan Kinesio Taping.

\section{Diskusi}

Hasil penelitian ini sesuai dengan penelitian yang dilakukan oleh Huang et al mengenai pengaruh penggunaan Kinesio Taping terhadap aktivitas otot dan vertical jump performance. Huang et al menemukan bahwa setelah 30 menit penggunaan Kinesio Taping terjadi peningkatan vertical ground reaction force (VGRF) dan electromyographic (EMG) m.gastrocnemius saat melakukan tes vertical jump. Hal ini disebabkan karena adanya peningkatan aktivitas otot dan sendi setelah penggunaan Kinesio ${ }^{\circledR}$ tex tape yang menyebabkan terjadinya peningkatan pada VGRF dan EMG. ${ }^{5}$

Penelitian yang dilakukan oleh Lemos et al menunjukkan terjadinya peningkatan kekuatan genggaman tangan kiri yang bermakna secara statistik setelah 30 menit, 24 jam, dan 48 jam penggunaan Kinesio Taping, serta kekuatan genggaman tangan kanan setelah 24 dan 48 jam setelah penggunaan Kinesio Taping. Regangan pada Kinesio Taping akan menimbulkan tegangan pada kulit kemudian meningkatkan rangsangan pada mekanoreseptor sehingga terjadilah peningkatan unit motorik yang terlibat pada saat kontraksi otot yang menyebabkan terjadinya peningkatan kekuatan otot. ${ }^{11}$

Penelitian Kim dan Seo mengenai pengaruh penggunaan Kinesio Taping terhadap daya ledak otot anaerobik m.quadriceps femoris menunjukkan terjadi peningkatan daya ledak otot m.quadriceps femoris setelah penggunaan Kinesio Taping. Hal ini kemungkinan disebabkan karena timbulnya kerutan pada kulit akibat penggunaan Kinesio Taping sehingga terjadi peningkatan aliran darah yang dapat meningkatkan daya ledak otot. ${ }^{12}$ 


\section{Research Article}

Penelitian yang dilakukan Lumbroso et al membuktikan bahwa penggunaan Kinesio Taping dapat meningkatkan peak force m.gastrocnemius dan otot hamstring. Kinesio Taping yang ditempelkan pada kulit akan secara terus menerus memberikan tegangan pada kulit dan kemudian ke fascia superficialis hingga melewati ligamen pada bagian fascia profunda. ${ }^{12}$ Hasil penelitan Yeung et al menunjukkan jika penggunaan Kinesio Taping mempersingkat waktu yang dibutuhkan untuk menghasilkan puncak torsi (peak torque) selama ekstensi lutut secara isometrik. Hal ini kemungkinan berhubungan dengan rangsangan pada mekanoreseptor kulit. Rangsangan saraf perifer yang disebabkan oleh penggunaan Kinesio Taping menurunkan ambang rangsang dari motor neuron serta meningkatkan kontraksi dari muscle spindle dan eksitasi korteks motor sehingga dapat memfasilitasi proses rekruitmen dari unit motorik. ${ }^{14}$

Hasil penelitian ini menunjukkan bahwa terdapat perbedaan yang sangat bermakna antara selisih daya ledak dan kekuatan otot quadriceps femoris 20 menit dengan sebelum penggunaan Kinesio Taping dan 24 jam dengan sebelum penggunaan Kinesio Taping. Ini membuktikan bahwa efek fasilitasi dari Kinesio Taping sudah ada sejak 20 menit setelah pemasangan dan semakin meningkat hingga 24 jam setelah pemasangan Kinesio Taping. Hal tersebut menunjukkan bahwa efek Kinesio Taping segera setelah pemasangan belumlah optimal, ini dapat menjelaskan beberapa hasil tidak signifikan pada beberapa penelitian lain yang meneliti efek Kinesio Taping segera setelah pemasangan. ${ }^{6,7}$

Tes yang dilakukan 24 jam setelah pemasangan Kinesio Taping masih menunjukkan hasil lebih baik dibandingkan tes 20 menit setelah pemasangan, hal tersebut memunculkan dugaan bahwa Kinesio Taping lebih baik bila dipakai beberapa waktu sebelum aktivitas, bukan menjelang aktivitas baik itu aktivitas biasa maupun aktivitas olahraga. Keterbatasan penelitian ini adalah belum dapat mengidentifikasikan waktu yang paling optimal untuk melakukan aktivitas setelah pemasangan Kinesio Taping, sehingga perlu dilakukan penelitian lebih lanjut dengan menggunakan lebih banyak perbedaan waktu pemasangan.

\section{Simpulan}

Penggunaan Kinesio Taping meningkatkan daya ledak dan kekuatan otot quadriceps femoris 24 jam setelah penggunaan lebih baik dibandingkan 20 menit setelah penggunaan Kinesio Taping pada laki-laki dewasa non atlet. Pemakaian Kinesio Taping akan memberikan hasil lebih baik bila dilakukan antara 20 menit hingga 24 jam sebelum aktivitas. 


\section{Research Article}

\section{Daftar Pustaka}

1. Moore KL, Dalley AF, Agur AMR. Anterior and medial regions of thigh, In : Taylor C, editor. Moore Clinicaly Oriented Anatomy. Philadelphia: Lippincott Williams \& Wilkins; 2014. p.545-62.

2. Fratocchi G, Mattia FD, Rossi R, Mangone M, Santilli V, Paoloni M. Influence of Kinesio Taping applied over biceps brachii on isokinetic elbow peak torque. A placebo controlled study in a population of young healthy subjects. J.Sci Med Sport. 2012;1 (3):245-5.

3. De Hoyo M, Àlvarez-Mesa A, Sañudo B, Carrasco L, Domínguez S. Immediate Effect of Kinesio Taping on Muscle Response in Young Elite Soccer Players. Journal of Sport Rehabilitation.2013;22(1):53-8.

4. Slupik A, Dwornik M, Bialoszewski D, Zych E. Effect of Kinesio Taping on Bioelectrical Activity of Vastus Medialis Muscle. Preliminary Report. Ortopedia Traumatologia Rehabilitacja.2007;6(6):644-7.

5. Huang CY, Hsieh TH, Su FC. Effect of the Kinesio Tape to Muscle Activity and Vertical Jump Performance in Healthy Inactive People. Biomedical Engineering Online. 2011;10:70-11.

6. Fu TC, Wong AMK, Pei YC, Wu KP, Chou SW, Lin YC. Effect of Kinesio Taping on Muscle Strength in Athletes-A Pilot Study. Journal of Science and Medicine in Sport.2008;11:198-3.

7. Chang HY, Chou KY, Lin JJ, Lin CF, Wang CH. Immediate effect of forearm Kinesio Taping on maximal grip strength and force sense in healthy collegiate athletes. Physical Therapy in Sport.2010;11(4):122-7.

8. Kase K. KT 1 and 2 workbooks. Kinesio ${ }^{\circledR}$ Taping Association International; 2008.

9. Haff GG dan Dumke C, Laboratory Manual for Exercise Physiology, $1^{\text {st }}$ ed. Human Kinetics; 2012.

10. Juneja H, Verma SK, Khannas GL. Isometric Strength and Its Relationship to Dynamic Performance : A Systematice Review. Journal of Exercise Science and Physiotherapy. 2010;6(2):60-10.

11. Lemos TV, Pereira KC, Celedonio CP. The Effects of Kinesio Taping in Handgrip Strength. J Phys Ther Sci. 2015;27(3):567-4.

12. Kim DY, Seo BD. Immediate Effect of Quadriceps Kinesio Taping on the Anaerobic Muscle Power and Anaerobic Threshold of Healthy College Students. J PhysTher Scie. 2012;24(9): 919-5.

13. Lumbroso D, Ziv E, Vered E, Kalichman ML. The Effect of Kinesio Tape Application on Hamstring and Gastrocnemius Muscles in Healthy Young Adults. Journal of Bodywork and Movement Therapies.2014;18(1):130-9.

14. Yeung SS, Yeung EW, Sakunkaruna Y, Mingsoongnern S, Hung WY, Fan YL, Iao HC. Acute Effects of Kinesio Taping on Knee Extensor Peak Torque and Electromyograpic Activity After Exhaustive Isometric Knee Extension in Healthy Young Adults. Clin J Sport Med. 2014;25(3):284-7. 